\title{
\ل
}

\section{O gesto do olhar do espectador contemporâneo: nem santo nem bode, emancipado}

\author{
Martha de Mello Ribeiro \\ Universidade Federal Fluminense \\ melloribeiro.uff@gmail.com
}

Existe teatro sem espectador? Pergunta-armadilha que se instalou como motor para novas e radicais experiências no campo das artes da cena, inflamando o imaginário teatral da segunda metade do século $X X$, resultando em inúmeras experiências entre a negação ou a afirmação do pressuposto de inexistência do teatro sem o espectador. Os notórios representantes do assim denominado "Novo Teatro", em sua proposta de rup-tura radical com as formas dramáticas, materializada nos happenings dos anos cin-quenta, se posicionaram contra a ideia tradicional de espectador. A separação entre palco e plateia não é só questionada, mas principalmente vista como responsável por alienar o espectador de si. Incapaz de agir, fixo em um quadro, este se deixaria usurpar do seu poder contestador e de sua capacidade intelectual. Mas por que o mecanismo de funcionamento do teatro - olhar a cena - passa a ser tão questionado e mesmo execrado? Para os acusadores, como o espectador desconhece o processo de produção da obra, não participando ativamente desta, ele seria um ignorante. Ignorar é ausência de conhecimento, aquele que ignora não só não conhece suas próprias capacidades, como é facilmente levado ao erro, tomando o falso como verdade. Ao espectador, to-lhido de sua capacidade de agir, submetido a uma posição passiva, só lhe caberia um papel: se envolver com a ilusão teatral, sem questioná-la. Olhar estaria assim condici-onado, por este pressuposto, ao campo da ilusão e da não ação - campo este diame-tralmente oposto ao campo corpóreo do agir, da ação; por isso as inúmeras tentativas de envolvimento físico do espectador nos happenings, até mesmo pela violência, cul-minando inclusive em diferentes tentativas da expulsão do próprio espectador.

A forma mais radical de se estabelecer com os espectadores uma relação imediata, física mesmo, no uso da força e do choque emocional, veio com os happenings. Para conseguir a adesão "ativa" do espectador, eliminou-se a distância palco e pla- 
teia, obje-tivando uma reação corpórea mais imediata e intensa. Grande parte do fenômeno utilizou como estratégia ações "reais" como forma de suscitar o medo: espirrar água e detergente em pó nas pessoas; uso de ruídos ensurdecedores; desconforto físico, como ficar espremido numa sala ou se ver em apuros entre uma serra elétrica e um ventila-dor ${ }^{1}$. Tudo para arrancar o espectador de sua inércia e passividade. Para Susan Sontag, a agressão ao público parece "fornecer, na falta de alguma outra coisa, a espinha dorsal dramática do happening", acrescentando que esta forma artística, caracterizada por "situações de dissociação mecânicas", termina por nos fazer rir e, "como toda comédia precisa de um bode expiatório [...] no happening, este bode expiatório é o público" (1987, p. 308 e 317). Essas práticas de violência emocional ao público, como artifício para criar na cena o real presente e tirá-lo de sua suposta passividade, usando da força, resulta não em uma maior participação ativa por parte do espectador, com a conse-quente eliminação de uma alienação de si, mas em seu oposto: obrigando o espectador a participar da ação no palco, faz-se deste um refém. Sem liberdade de escolha, onde lhe é negada toda e qualquer autonomia, este se transforma em um bode expiatório e, como todo bode expiatório, está fadado ao desaparecimento. Sobre o refém, nos diz Baudrillard (1996, p. 31): "Nem morto nem vivo, o refém está suspenso por um prazo incalculável. [...] ele está além da alienação, além dos termos da alienação e da troca. Ele está em estado de exceção radical [...] foi tirado do próprio destino".

Sem o jogo entre identificação e distanciamento, próprio à cena, não apenas elimina-se a teatralidade, mas o próprio real deixa de existir, pois todo acesso ao real se dá por sua divisão. Conforme entende Badiou: não há apenas uma divisão entre real e artifício (ou semblante), mas, e o que é fundamental, há a divisão do próprio real, "visto que há um real do semblante" (2017, p. 24). Absorvidos pelo "real" da ação presente e transformados em bodes expiatórios, o espectador, aprisionado na anestesia emocional de uma violência extrema ou de um excesso de real ${ }^{2}$, , termina por trocar o real pelo real do semblante. Nesta aterradora tentativa da

$1 \quad$ Espetáculo Spring Happening, de Allan Kaprow, apresentado em 1961 na Reuben Gallery.

2 A companhia italiana Societas Raffaello Sanzio nos oferece o extremo do real em muitos de seu espetáculos. Talvez o caso mais extremo seja a montagem de "Giulio Cesare" que assisti em março de 2016 durante a Triennale di Milano, na qual uma sonda ótica é introduzida na cavidade nasal de um dos atores (Sergio Scarlatella) até sua glote, projetando numa tela todo o percurso do endoscópio para nos mostrar a vibração das cordas vocais na produção da voz. 
cena contemporânea em desaparecer com o artifício da cena, através da evidência do real, ou melhor, de um hiper-real, o que ocorre é um duplo desaparecimento: o desaparecimento da cena da ilusão e do próprio real. Sem o necessário ato desta dupla divisão do real, mencionada por Badiou, não se identifica este "real do semblante". Sem este desmascaramento, dado pelo distanciamento, se impede o processo de acesso ao real. O principal sintoma da arte à crise da representação foi a rejeição de todo artificio, em tentativas de substituição da cena da ilusão por uma busca desenfreada pelo real. Todo espetáculo tornou-se um escândalo, ser espectador torna-se também um escândalo, mas se toda "paixão pelo real culmina no seu oposto aparente, num espetáculo teatral", como observado por Slavoj Zizek (2002, p. 26), podemos dizer que o escândalo é útil para dissimular a lógica do simulacro que rege nossa sociedade, onde nem mesmo o teatro quer ser teatro. Não é uma coincidência que o escândalo fabrique bodes expiatórios (neste caso aqui o espectador).

Se a crítica ao gesto do olhar ${ }^{3}$ é um tema do teatro contemporâneo, seu fenômeno é antigo e remonta há pelo menos 2.500 anos, lá nos escritos platônicos contidos na "Alegoria da Caverna", no qual o filósofo grego contrapõe a Verdade (mundo das Ideias) à ilusão (mundo Sensível). A desconfiança sobre o gesto do olhar ao mundo sensível, onde encontra-se a arte, aparece de forma ainda mais contundente em suas críticas ao teatro. Considerado por sua natureza mimética um fenômeno que produz enganos por simular diante do olhar uma coisa que não é, o teatro é visto por Platão como extrema-mente nocivo à pólis, pois o que ele simula pode parecer ainda mais real do que a própria coisa que ele simula. Platão condena a mimese por ela criar uma lógica que substitui o real pelo simulacro (sinais do real), levando aquele que olha ao erro, pois passa a acreditar no falso em detrimento do real. Essa crítica ao gesto do olhar se manteve ao longo da história do teatro ocidental. Por exemplo, no período medieval, o gesto do olhar, aderente ao espetáculo, foi extremamente rechaçado pelos cristãos, por entender que a visão era a base da corrupção moral. Como muito bem observado pelo estudioso Luigi Alllegri (2015, p. 41), a condenação da igreja cristã ao espetáculo re-sultou em

3 O uso da palavra "gesto" somada ao verbo olhar nos ajuda a deixar mais claro ao leitor nosso entendimento que olhar é sempre uma ação, é da natureza do agir. Acreditamos que dar ao olhar uma propriedade física, como gesto, elimina-se qualquer possibilidade de se entender o olhar como algo de natureza passiva ou contemplativa somente. 
perseguições e campanhas ideológicas contra o teatro e contra os profissio-nais da cena. Essa campanha difamatória foi responsável pelo apagamento no período da própria noção de representação, tal foi a destruição impetrada ao teatro enquanto instituição cultural. $O$ estudioso nos oferece um panorama da degradação moral sofrida pelo teatro e o desprezo dos escritores pelas formas espetaculares do período (século III), em sua maioria espetáculos circenses e de pantomima, com a participação de mulheres em cenas de forte apelo sexual. Formas que não correspondiam nem aos interesses e nem aos ideais cristãos.

O que gostaríamos de chamar a atenção, baseado nos estudos de Allegri sobre o destino do teatro no período medieval, é que a crítica não era direcionada apenas para o con-teúdo considerado aviltante, porque este poderia ser mudado; a crítica se direcionava de forma contundente para a própria constituição do espetacular, por esta se tratar de uma performance endereçada ao olhar ${ }^{4}$. O problema estava no centro do espetacular, na relação ator e espectador, isto é, no gesto do olhar, no fascínio que qualquer espe-táculo, com suas imagens visuais, corporais e emocionais, poderia provocar. Allegri cita escritores cristãos da época, como Tertulliano, que, no tratado "De spectaculis", funda-menta seu discurso afirmando que o que pertence tipicamente ao espetáculo é a cor-poreidade: gesto e movimento do corpo. E, como a corporeidade é o mal para a doutrina cristã, podemos concluir que o espetáculo, na sua ostentação de um corpo que se deixa olhar diretamente, é duplamente o mal. É justamente este ponto sobre a corporeidade que nos interessa sublinhar, pois o corpo em cena só se comunica se endereçado ao olhar, se houver como perspectiva o olhar do outro. Para os escritores da época medieval, o olhar não era algo passivo, oposto à ação, olhar era também uma forma potente de agir: o olhar podia tocar e se deixar tocar pelo corpo exposto à visão. Mais do que um jogo entre esconder e revelar, olhar era um gesto que provocava uma verdadeira experiência física, insuflada pelo artifício das paixões. Não havia uma nítida oposição entre olhar (passivo) e agir (ativo). Olhar era perturbador porque provocava no espec-tador paixões e comoções, que são corpóreas (ainda que enganosas). Conforme teste-munha Santo Agostinho nas "Confissões" (2005, p. 58):

$4 \quad$ Entendemos que todo espetáculo em sua materialidade concreta é uma performance, onde os atores, diante de espectadores que olham, executam ações vocais e gestuais, endereçadas a estes. 


\begin{abstract}
Arrebatavam-me os espetáculos teatrais, cheios de imagens das minhas misérias e de alimento próprio para o fogo das minhas paixões. [...] o espectador anseia por sentir esse sofrimento que afinal para ele constitui um prazer. Que é isto senão rematada loucura? Com efeito, tanto mais cada um se comove com tais cenas quanto menos curado se acha de tais afetos (deletérios).
\end{abstract}

Observa-se na fala de Agostinho o fundamento da relação que liga o espectador ao espetáculo, um jogo entre identificação e distanciamento, proporcionado na balança entre o real e o ficcional. Este jogo provoca uma agitação na alma do espectador. Agitar vem do verbo agir, do latim agere, que significa pôr em movimento. Pôr a alma em movimento é o oposto do que se deseja no comportamento de um cristão, prisioneiro da regra do comedimento e do domínio das paixões. Há assim, no gesto do olhar, uma nítida forma de agir que embaralha o jogo de oposição entre ativo (agir) e passivo (olhar). A condenação ao teatro sempre esteve ligada, em suas mais diferentes formas e crenças, à condenação ao gesto do olhar. Seja com Platão ou com os pensadores cristãos, seja no mundo moderno, com os teóricos do drama burguês, que encarrega-ram o teatro do "real" ou ainda com o teatro da performance, que investiu na anticena do hiper-real, todos sempre se posicionaram contra o olhar. Mas, enquanto os antigos entendiam que o olhar era também um gesto, os criadores do drama burguês, junto aos artistas da vanguarda, criadores dos happenings e das performances, passaram a crer que a natureza do olhar era somente passiva. Se no mundo antigo o gesto do olhar condenava o espectador à agir na ignorânica, levado pelas aparências, o argumento que condena o espectador contemporâneo é inverso: o olhar passa a ser destituído do gesto, e o especatdor, condenado à estar sentado, não possui mais a capacidade de agir, permanecendo passivo, alienado de si mesmo. No entanto, esses argumentos que associam a passividade ao que é negativo e a atividade ao que é positivo não levam em consideração os movimentos da alma, ações internas invisíveis que geram conhecimento.

Por exemplo, a ideia de que o teatro é uma forma comunitária exemplar, e que para recuperar essa essência perdida é necessário abolir o espetáculo, é um argumento muito criticado por Rancière. Ele observa que práticas do novo teatro, em sua tentativa de reconquistar um espectador ativo, partem de uma suposta desigualdade entre as partes, se propondo a ensinar o espectador a deixar de ser espectador para se "torna-rem agentes de uma prática coletiva" (2012, p. 13). O espetáculo 
ou a performance não é a transmissão direta do saber do artista ao espectador, há uma terceira coisa, como afirma Jacques Rancière, estranha a ambos. Contrário à ideia de reapropriação de uma relação perdida do ser humano consigo mesmo, que se partiu neste processo de separação palco e plateia, Rancière lança uma ideia de emancipação que não recusa a mediação, essa terceira coisa desconhecida, e nem exige do teatro esse lugar de assembleia comunitária: "todo espectador é já ator de sua história; todo ator, todo homem de ação, espectador da mesma história". Isto é, a emancipação é "o embara-Ihamento da fronteira entre os que agem e os que olham" (Rancière, 2012, p. 21 e 23). Contra esse jogo de oposições e equivalências, o filósofo contrapõe a ideia de uma experiência estética que possa romper com essa lógica de dominação, referindo-se ao livre jogo do espectador, que se vê diante de uma forma estética endereçada a ele.

Recorremos a Rancière para nos ajudar a desvelar o que estaria por trás da crença contemporânea de que olhar seria oposto a agir (ação). Para o filósofo, tal julgamento se construiu a partir de um equívoco de análise, responsável por originar duas grandes fórmulas antagônicas, que têm em comum o desejo de um teatro sem espectadores. Por um lado, observa-se a proposta de "arrancar o espectador ao embrutecimento do parvo fascinado pela aparência e conquistado pela empatia que o faz identificar-se com as personagens da cena" - o que o tornaria um observador ou experimentador cientí-fico; por outro lado, instiga-se a participação ativa do espectador "retirado da posição de observador que examina calmamente o espetáculo que lhe é oferecido. [...] arrastado para o círculo mágico da ação teatral" -, tornando-o, assim, parte ativa da experiência, empoderado de sua energia vital. Como exemplo desta polaridade, cita o teatro épico de Brecht e o teatro da crueldade de Artaud - "inquirição distante e participação vital" (Rancière, 2012, p. 10). Duas formas distintas de crítica ao espectador que age por denegação, se deixando envolver pela ilusão cênica ${ }^{5}$. Em outras palavras, e de forma mais abrangente, podemos dizer que essa rejeição generalizada ao espetáculo, e consequentemente ao gesto do olhar do espectador, aponta para duas concepções distintas de arte: uma que rejeita os mecanismos de teatralidade, da ilusão cênica, investindo numa experiência dita ativa e mágica; outra que torna estes mecanismos excepcionalmente visíveis, buscando distanciar o espectador de qualquer envolvimento com

5 Sobre o verbete denegação, cf. Dicionário de Teatro, de Patrice Pavis (São Paulo: Editora Perspectiva, 1999. p. 89-90). 
a cena da ilusão. Em comum, ambas buscam ter acesso ao real, abolindo a ideia tradicional de espectador. Rejeitar o gesto do olhar é um caminho que estabelece uma relação desi-gual, hierárquica, entre quem age e quem olha; antípoda ao ideal de um espectador emancipado ${ }^{6}$.

Se no mundo medieval, onde ainda havia uma clara separação entre o real e o artifício, a condenação do espetáculo se deu em função da relação ativa entre a cena e o espec-tador que olha, que, de tão fascinado pela visão dos corpos, se sentia verdadeiramente tocado (posto em movimento, em ação) pelo artifício da cena, afastando-se para os cristãos da verdade moral; no mundo contemporâneo (pós-moderno) será o questiona-mento radical do que é o real que irá condenar a visão do espectador a um excesso de real. Para Jean Baudrillard, a extrema exposição do real foi a maneira que a arte en-controu para sair de si mesma, negar a si mesma, mas, quanto mais ela investe nesta direção, "mais ela se hiper-realiza, mas ela se transcende em sua essência vazia" (1996, p. 9). Nas teorias e experimentos práticos performativos que se utilizam do choque emocional, observa-se a passagem do ato teatral para um ato apenas, numa espécie de sintoma deste desmoronamento do real - onde tudo se quer real. Como vai senten-ciar Zizek, o ato de se cortar numa performance "representa uma estratégia desesperada de voltar ao real do corpo", uma espécie de "afirmação da própria realidade" (2002, p. 26). O pós-moderno em sua paixão pelo real colocou em dúvida a realidade dos corpos, colocou em dúvida a potência do olhar.

Segundo Baudrillard, o real desaparece no momento em que tudo se torna real, no momento em que nada mais existe como ideia, sonho ou fantasia. É neste momento que tudo se torna um simulacro de si mesmo: no mundo pós-moderno, responsável por um questionamento radical da realidade e de sua natureza de construção, não há uma comunicação, e sim uma "contaminação de tipo virótica" (Baudrillard, 2001, p. 31), onde tudo passa de um para o outro sem mediação, sem distância, sem encanto, sem canibalismo. Para Hans-Thies Lehmann, em seu Teatro pós-dramático (2007), uma das principais características do teatro pósdramático (ou teatro performativo, na nomen-clatura de Josette Fèral) está no desejo de imediatez da experiência compartilhada en-tre o artista e o espectador. A proposta não é criar

6 Cf. o artigo "Espanto e Reconhecimento na peça didática "A decisão": tentativas para entrever o modo de experiência do espectador no teatro contemporâneo" (Revista Sala Preta, v. 14, n. 1, 2014. Disponível em: <http://dx.doi.org/10.11606/issn.2238-3867.v14i1p104-112>). 
um universo fictício, mediado por imagens, mas de realizar uma experiência real, imediata. Este desejo do real, em seu sintoma de rejeição ao espetáculo, para além da fuga da arte no hiper-real, também se constrói na ideia de uma traição à sua essência original: ser uma ação comunitária. É a partir deste argumento que recuperamos as análises de Rancière sobre a emancipação do espectador.

Oposta aos ideiais de eliminação da separação palco e plateia, a prática da emancipação comprova, na separação, a igualdade das inteligências. Não se trata de transpor o abismo entre a ignorância do espectador e o saber do ator, mas aventurar-se no gesto do olhar, que também é ação, que também é um saber. As ideias de Rancière sobre o espectador emancipado contrariam o pressuposto de uma desigualdade entre as partes. É a partir deste diagnóstico de crítica à rejeição da teatralidade (entendida enquanto agente de deformação do verdadeiro teatro, isto é, do corrompimento de sua natureza de assembleia) ou de seu excesso (na rejeição de qualquer laço emocional entre as partes) que o filósofo começa a investir na ideia de emancipação para o espectador, reformulando o problema para além dos jogos de equivalências e oposições. Arrancar com a performance o espectador de sua atitude passiva, lançando-o ativamente na cena, é, para Rancière, praticar uma cena embrutecedora: "Desqualifica-se o especta-dor porque ele não faz nada, enquanto os atores em cena ou os trabalhadores lá fora põem seu corpo em ação" (2012, p. 17). Nada mais contrário aos pressupostos de emancipação.

A emancipação só pode começar a partir do questionamento desta oposição entre olhar (passivo) e agir (ativo), ou seja, questionando esta estrutura de poder, de sujeição e dominação. Olhar é agir, é se expor, é se aventurar, é atravessar e ser atravessado. Como exemplo de uma lógica embrutecedora na arte, citamos o encenador que deseja aprisionar a experiência do espectador naquilo que ele quer transmitir. Uma vez, du-rante um ensaio de um diretor teatral muito conhecido aqui no Brasil7, havia uma cena onde alguns atores empilhavam livros de forma muito lenta, formando uma torre. Ao comentar a cena com o diretor, relacionei o ato à construção mecânica de uma grande biblioteca e à nossa necessidade de acumular informação, enfraquecendo, por outro lado, a experiência empírica. Ao posto que o encenador rejeitou minha interpretação, dizendo que a cena se tratava de uma alusão às Torres Gêmeas de Nova York. Trata-se de um exemplo claro do

7 Como o referido diretor não foi consultado sobre a possibilidade de menção ao seu nome no artigo, resolveu-se omi-tir sua identidade para não causar constrangimentos. 
que Rancière vai apontar como "lógica do pedagogo embru-tecedor, a lógica da transmissão direta e fiel" (Rancière, 2012, p. 18). Por esta lógica, o espectador deve ver somente aquilo que o encenador deseja que ele veja, eliminando a possibilidade de troca. Impõe-se assim uma estrutura de poder que distribui capaci-dades e incapacidades, roubando do espectador sua capacidade de ser afetado e de afetar, isto é, de também construir/dirigir a cena, agir sobre ela.

Muito deste prejuízo sobre o espectador se justifica tendo em vista o modelo de espec-tador forjado pelos ideais da cena burguesa, segundo o qual o sujeito estava dado antes mesmo da experiência artística; modelo que denomino como espectador-santo. O sig-nificado do termo santo no Dictionary of the Bible (1909) parte de um conceito de separação, de remoção, o que é particularmente interessante para se entender a configuração espacial do espectador na cena naturalista: uma espacialidade absoluta-mente separada da configuração da obra. O espectador-santo, ao entrar no teatro, é automaticamente separado de sua realidade cotidiana particular, ou profana, para par-ticipar de um conjunto sagrado, o teatro. Idealizado, o espectador-santo, separado do comum, transforma-se em uma entidade pura, incapaz de contaminar a experiência artística, pois somente a impureza é transmissível e poluente. O que quer dizer que as situações representadas devem responder à perspectiva soberana e subjetiva do artista e jamais ser contaminada pela experiência única, ou emancipada, de um espectador em sua individualidade. A tarefa do espectador-santo é decifrar os signos da cena e, consequentemente, aceitar certa visão de mundo como verdade. É o que Tassinari (2001) vai denominar como "intersubjetividade analógica" ao se referir ao espaço na-turalista na arte. Ainda que o espectador esteja diante da cena, que foi endereçada a ele, seus criadores (seguidores de uma lógica embrutecedora) têm a convicção de que esta não será contaminada pelo agir do espectador, isto é, pelo gesto do olhar de cada um dos diferentes espectadores que ali estão.

A ilusão deste modelo de espectador passivo é a crença de que este não compartilha com a obra um espaço comunitário do sensível, ou seja, de que o espectador, ao ver, deixa de fazer (agir): "A intersubjetividade, no naturalismo, é analógica. $\mathrm{O}$ que se passa para um sujeito deve se passar igualmente para outro. O espectador se encaixa numa visão que não é a dele e a esposa como se fosse sua" (Tassinari, 2001, p. 148). O modelo naturalista tem a ilusão de promover modos de "ser em comum", excluindo, apagando ou incorporando diferenças, num espaço aparente- 
mente consensual. No en-tendimento de Tassinari, a cena que não se quer unívoca entende que a arte se forma na abertura de um espaço "intersubjetivo conjuntivo": "A obra não imita uma visão e nem imita em conformidade com uma visão, mas se comunica com o espectador numa espécie de face a face que tem no mundo em comum o seu solo e sua garantia" (Ibi-dem). A experiência do espectador pertence a esta espacialidade intersubjetiva conjuntiva, este não é absorvido para dentro da obra, nem anulado por ela, e também não está excluído de seu fazer, pois a obra só existe no espaço do mundo, isto é, em sua performatividade. Incluídos num espaço comum de existência, o espectador, o criador e a obra criam um espaço intersubjetivo, uma rede intersubjetiva onde o fazer e o ver estão muito além de uma oposição entre atividade e passividade. Dar ênfase ao gesto do olhar na experiência do espectador é se afastar tanto da ideia de um espectador-santo quanto da ideia de um espectador-bode, é ir ao encontro do espectador emancipado!

\section{Referências}

AGOSTINHO, Santo. Confissões. Bragança Paulista: Editora Universitária São Francisco, 2005.

ALLEGRI, Luigi. La teatralità medievale. In: ALLEGRI, Luigi et al. Breve storia del teatro per immagini. Roma: Carocci editore, 2015.

BADIOU, Alain. Em busca do real perdido. Belo Horizonte: Autêntica editora, 2017.

BAUDRILLARD, Jean. Senhas. Rio de Janeiro: Difel, 2001.

As estratégias fatais. Rio de Janeiro: Rocco, 1996.

HASTINGS, James. Dictionary of the Bible. New York: C. Scribners Sons, 1909.

KIRBY, Michael. Happening. Bari: Donato editore, 1968.

LeHMANN, Hnas-Thies. Teatro pós-dramático. São Paulo: Perspectiva, 1999.

PAVIS, Patrice. Dicionário de Teatro. São Paulo: Perspectiva, 1999. 
RANCIÈRE, Jacques. O espectador emancipado. São Paulo: Martins Fontes, 2012.

RIBEIRO, Martha. Espanto e Reconhecimento na peça didática "A decisão": tentativas para entrever o modo de experiência do espectador no teatro contemporâneo. Revista Sala Preta, v. 14, n. 1, 2014. Disponível em: <http://dx.doi.org/10.11606/ issn.2238-3867.v14i1p104-112>.

SONTAG, Susan. Contra a interpretação. Porto Alegre: L\&PM, 1987.

TASSINARI, Alberto. O Espaço Moderno. São Paulo: Cosac Naify Edições, 2001.

ZIZEK, Slavoj. Bem-vindo ao deserto do real. São Paulo: Bomtempo Editorial, 2011. 